\title{
About the Regions and Regional Conferences of Europe On the occasion of the Third Caucasian Mathematics Conference (CMC)
}

Betül Tanbay (Boğaziçi University, Istanbul, Turkey)

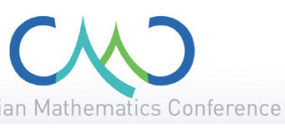

Good old Europe, good Old World. Who are you? What are you? Living in Istanbul means for millions commuting back and forth between Europe and Asia every day. But instead of the long traffic queues on the bridges, it is more advisable to take a Bosphorus boat between these continents, especially if you want to think about geography or mathematics.

Mathematicians seek precise definitions, yet Europe remains quite undefinable. Political changes have too great an influence for a stable definition. The European Mathematics Society (EMS) was probably the projection to Mathematics of the EU project. It is comforting to see that the EMS is not destabilised as easily and that it has a wider and more stable understanding of Europe. At the 25th anniversary of the EMS, I remember its President Pavel Exner talking about 2000 years of mathematics in Europe, and evidently he was including Asia Minor, Mesopotamia and the Mediterranean Sea. Yet, national histories have different accounts. I often ask during my lectures what it is that makes a student from Izmir not feel like they are from the same country as Thales.

Two recent conferences made me feel like writing about this Europe in a larger context: the third Caucasian Mathematical Conference (CMC) and the Women Mathematicians of the Mediterranean Shores. The latter was in Bled, Slovenia in September and brought together mathematicians from all around the Mediterranean Sea. Another occasion to share common values, be it maths or great food.

CMC is already 5 years old. At the opening of the third one last August in Rostov-on-Don, Russian Federation, the CMC-III-Chair Armen Sergeev said: "A first is an occurrence, a second a coincidence, but a third is tradition." We all hope that it does become a tradition. The mathematical signs are so far positive.

The idea of a CMC was first pronounced at the EMS presidents meeting in Aarhus, Denmark in 2013, and the then EMS President Marta Sanz-Solé immediately asked the Georgian Mathematical Union President Roland Duduchava and EMS Vice-President Armen Sergeev to form a founding team with myself, at that time President of the Turkish Mathematical Society. It took us one meeting at the Istanbul Center for Mathematical Sciences overlooking the Bosphorus to set up the structure of CMC and its "raison d' être": Under the auspices of the European Mathematical Society, the mathematical societies of Armenia, Azerbaijan, Georgia, Iran, Russia and Turkey come together to create the Caucasian Mathematical Conference (CMC) project and to get to know each other, share their work, research and results, and jointly navigate new areas of research in mathematics.

There are three committees: the steering committee with representatives from the six national mathematical societies and from EMS; the scientific committee chosen from previous invited speakers, which chooses seven "invited speakers" and twelve "young speakers" from the propositions made by these societies; and the organizing committee.

The first Caucasian Mathematical Conference took place in 2014 in Tbilisi, Georgia with more than 150 registered mathematicians from these six countries and more. At the conference dinner, mathematicians from Azerbaijan, Armenia and Turkey joined each other to perform the famous Caucasian dances; living together was not such an impossible task! We could do mathematics, eat, drink and dance!

In September 2014, our first CMC was certainly not the centre of public attention. The world was busy with the NATO Summit that was held in Wales, UK the same week. Mathematics conferences and political summits are really different in essence. The goal of the summit was to provide "common security, prosperity and values", to come up with solutions to social and political nodes. In public, the rulers filled their discourse with

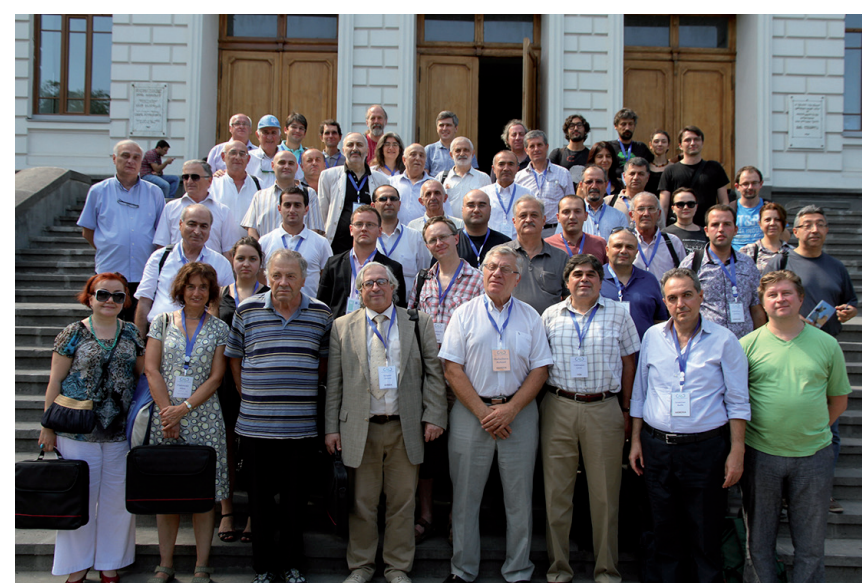

CMC-I, 5 September 2014, Tbilisi, Georgia. 


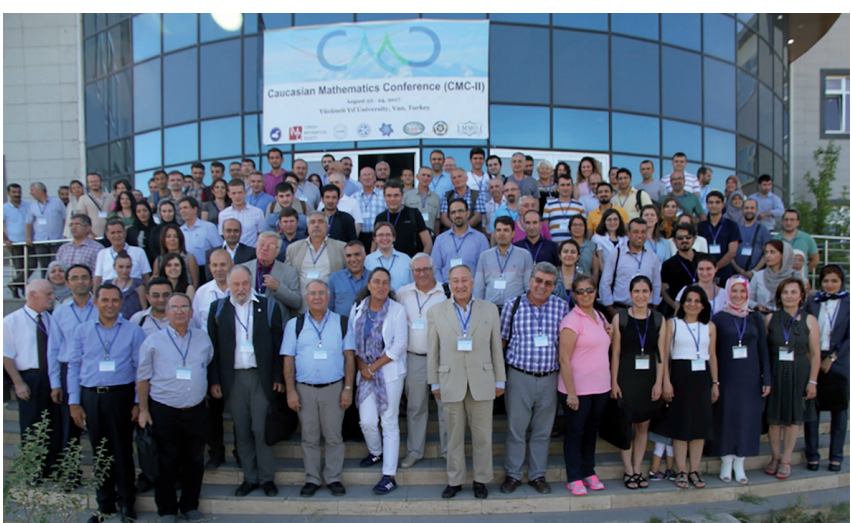

CMC-II, 22 August 2017, Van, Turkey.

the words "freedom," "human rights," "democracy" and "peace". Meanwhile, CMC shareholders made neither political nor hypocritical promises, but decided to hold the second conference in 2016 in Turkey, and chose the Yüzüncü Yil University in Van as the location: a meaningful barycenter for all the countries involved.

The events of Summer 2016 in Turkey obliged the organisers to postpone CMC-II until the following August. The meeting was held in 2017 with almost 200 participants from all countries. Can mathematical peace set an example for political peace?

Meanwhile, no NATO summit and no European Union summit has found solutions to nodes as promised, because the real decisions are taken behind closed doors. We have had to witness ugly negotiations around millions of people who have lost their homes. People having to leave their land... is this the destiny of the region?

Meanwhile, the CMC continues with the goal of becoming a tradition. At the Southern Federal University in Rostov this summer, mathematicians from 15 countries, including the "six", got together to listen to excellent talks, the EMS speaker being Ragni Piene, the first female invited speaker of the CMC series. I will skip the story of the President of the EMS becoming a Cossack on a boat ride on the quietly flowing Don, at least until our retirement. The steering committee had a meeting in a simple room at the Don Quixote Hotel where most participants were staying. All members were present. The first round of talks may have had some reminiscence of

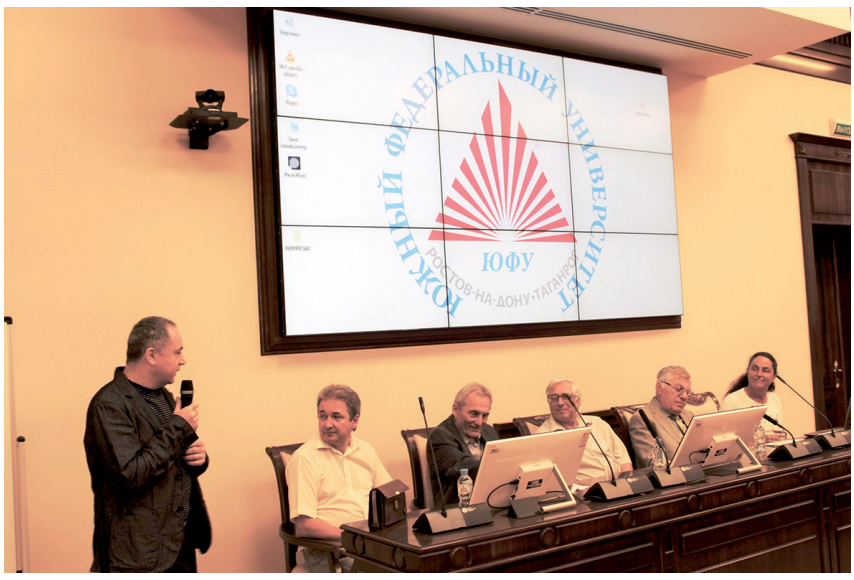

Opening CMC-III, 26 August 2019, Rostov-on-Don, Russian Federation.

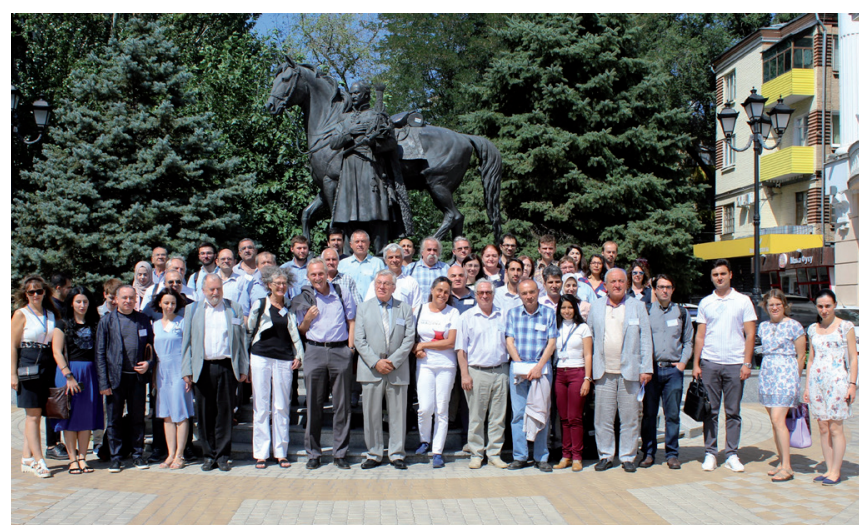

CMC-III, 26 August 2019, Rostov-on-Don, Russian Federation.

national reflexes, but it took less than a quarter of an hour to have the Azerbaijan representative Asaf Ghadiev proposing funding solutions for a summer school we would organise prior to CMC-IV to be held in Yerevan, Armenia in 2021. The steering committee also decided to have CMC-V in Azerbaijan, and the next in Iran. Hopefully, or "inşallah" as we commonly say in my neighbourhood.

What politicians discuss in meeting rooms is secret. What mathematicians discuss in meeting rooms is not secret but not easily communicable to the general public. Nevertheless, the fact that they set a "good example" by working together, overcoming the burden of borders and nationalities, generating positive energy in an atmosphere where the priority is the good of humanity and science deserves to become common knowledge.

While CMC is becoming a tradition, there are rumours that a Balkan Mathematics Conference will start, a BMC? From AMC to ZMC, I believe the European Mathematical Society has every reason to support such regional gatherings; they may not always achieve the prestige of an ECM, but they can be part of the sources that create the flow of excellent mathematicians.

In mathematics, the richer a theory, the harder it is to keep it both complete and consistent. Not very mathematical I know, but in this very case, I would compromise consistency. Instead of avoiding paradoxes, maybe we can just try to minimise them. The planet's most serious problems are becoming more and more independent of nationalities, so it might be a good idea to keep on working on getting together.

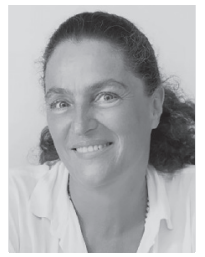

Betül Tanbay is a professor in Functional Analysis at the Boğaziçi University in Istanbul. She was founder and first co-director of the Istanbul Center for Mathematical Sciences. She was the first female president of the Turkish Mathematical Society, and she has also served and serves in many committees of the IMU or EMS. Tanbay received her undergraduate degree from ULP, Strasbourg in 1982, and graduate degrees from UC Berkeley in 1989 